\title{
Correction to: melatonin enhances antioxidant defenses but could not ameliorate the reproductive disorders in induced hyperthyroidism model in male rats
}

\author{
Hager M. Ramadan ${ }^{1}$ (D) $\cdot$ Nadia A. Taha ${ }^{1} \cdot$ Hodallah H. Ahmed ${ }^{1}$ \\ Published online: 28 December 2020 \\ (C) Springer-Verlag GmbH Germany, part of Springer Nature 2020
}

Correction to: Environmental Science and Pollution Research https://doi.org/10.1007/s11356-020-10682-7

The correct fig. $9 \mathrm{f}$ is presented in this paper.

The original article was corrected.

The online version of the original article can be found at https://doi.org/ 10.1007/s11356-020-10682-7

Hager M. Ramadan

hmagdy515@yahoo.com

1 Department of Physiology, Faculty of Veterinary Medicine, Cairo

University, Giza, Egypt 

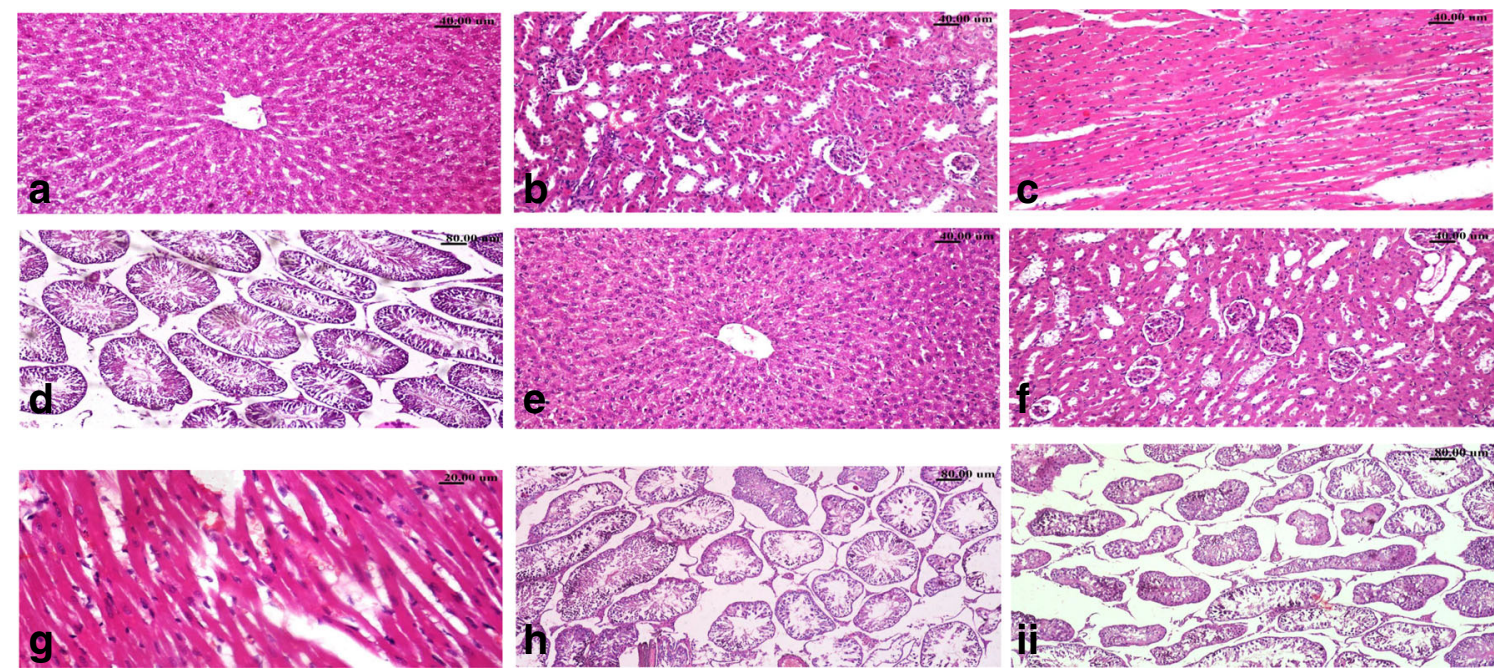

Fig. 9 H\&E stained sections. a-d Tissues' sections of L-thyroxine and $5 \mathrm{mg}$ melatonin co-administrated rats showing; a mild degree of hepatocellular necrobiotc changes, $\mathbf{b}$ moderate degeneration, necrosis and few desquamation of the renal tubular epithelial linings, $\mathbf{c}$ mild degree of cardiac muscle fibers' degeneration and hyalinization, and $\mathbf{d}$ testicular tissue with arrested spermatogenesis and interstitial edema. $\mathbf{e}-\mathbf{i}$ Tissues' sections of L-thyroxine and $10 \mathrm{mg}$ melatonin co-administrated rats showing; e near to normal appearance of hepatic parenchymal cells, f mild renal tubular epithelial cells' necrobiotic changes and few desquamated cells, $\mathbf{g}$ cardiac tissue showing good restoration of the cardiac muscle fibers with mild necrobiotic changes, and $\mathbf{h}$ and $\mathbf{i}$ testicular tissue with defective spermatogenesis and distortion (arrow) of some seminiferous tubules

Publisher's note Springer Nature remains neutral with regard to jurisdictional claims in published maps and institutional affiliations. 